\title{
Adaptive Support Ventilation as a Sole Mode of Mechanical Ventilation-An Observational Study
}

\author{
Rajbanshi LK, ${ }^{1^{*}}$ Dali $M,{ }^{2}$ Karki SB, ${ }^{1}$ Khanal $K,{ }^{1}$ Aryal $B,{ }^{1}$ Chapagain $K^{3}$
}

\section{Affiliation:}

1. Lecturer, Department of Anaesthesiology and Critical Care, Birat Medical College \& Teaching Hospital, Biratnagar, Nepal.

2. Associate Professor, Department of Pedodontics \& Preventive Dentistry, B. P. Koirala Institute of Health Sciences, Dharan-18, Sunsari.

3. Assistant Professor, Department Pharmacology, B. P. Koirala Institute of Health Sciences, Dharan-18, Sunsari.

\section{ARTICLE INFO}

\section{Article History}

Received : 4Aug, 2016

Accepted : 4Sep, 2016

Published : $20 \mathrm{Dec}, 2016$

(C) Authors retain copyright and grant the journal right of first publication with the work simultaneously licensed under Creative Commons Attribution License CC - BY 4.0 that allows others to share the work with an acknowledgement of the work's authorship and initial publication in this journal.

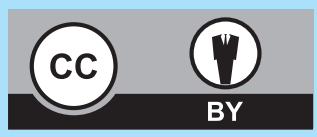

* Corresponding Author

Dr. Lalit Kumar Rajbanshi

$$
\text { Lecturer }
$$

Department of Anaesthesiology and Critical Care Birat Medical College \& Teaching Hospital, Biratnagar, Nepal Email: Ialitrajbanshi@gmail.com

\section{Citation}

Rajbanshi LK, Dali M, Karki SB, Khanal K, Aryal B, Chapagain K. Adaptive Support Ventilation as a Sole Mode of Mechanical Ventilation-An Observational Study. BJHS 2016;1 (1) 1:8-12.

\section{ABSTRACT}

\section{Introduction}

Adaptive support ventilation (ASV) is a close loop dual control mechanical ventilation mode. This mode can automatically change its parameters to weaning mode once the patient is actively breathing converting volume targeted pressure control mode to volume targeted pressure support mode. We aimed to observe the outcome of the patients ventilated with ASV as a sole mode in terms of duration of mechanical ventilation, duration of weaning from the ventilatory support and length of Intensive care unit (ICU) stay.

\section{Methodology}

We conducted a prospective observational study for the duration of six months (Sept 2015 to Feb 2016) to assess the clinical outcome of the patients ventilated by ASV as a sole mode of ventilation. The study conducted observation of 78 patients without chronic respiratory, renal, hepatic and neurological disease who were admitted in our intensive care unit for invasive ventilatory support.

\section{Results}

Out of the 187 patients who required invasive and noninvasive ventilation, only 78 patients fulfilled the criteria to be included in the study. It was observed that the mean duration of mechanical ventilation was 5.4 days while weaning as well as tracheal extubation was successful within 13 hours of initiation of weaning. The mean duration of ICU stay was found to be 6.3 days.

\section{Conclusion}

We concluded that the patient ventilated by ASV mode were effectively weaned without the need of changing the ventilator mode. However, the safety of ASV mode needs to be established by large randomized control trail in a wide spectrum of patients.

\section{KEY WORDS}

Adaptive support ventilation, closed loop ventilation, weaning 


\section{INTRODUCTION}

The adaptive support ventilation (ASV), also known as closed loop controlled ventilator mode is designed to operate as volume targeted pressure control as well as pressure support mode depending on the lung dynamics. The measurements regarding lung parameters like resistance, compliance, auto-PEEP are made continuously and are used as negative as well as positive feedback mechanism to adapt the changing lung physiology.

The minute ventilation is set by the operator according to the ideal body weight and the ventilator automatically determines the respiratory rate and tidal volume to be delivered to the patient depending on the negative and positive feedback mechanism. As ASV adapts the ventilator strategy according to the changing lung dynamics it significantly reduces the work of breathing and helps to achieve an optimal ventilatory pattern preventing auto PEEP, volutrauma and barotrauma. ${ }^{3}$

The machine calculates the minute ventilation according to the set ideal body weight of the patient and the operator usually selects the percentage of targeted minute ventilation to be delivered (usually 100\%). If the patient does not display any breathing effort, the ventilator will deliver the volume targeted pressure controlled breath to meet the targeted minute ventilation. if the patient has spontaneous breathing, ventilator will operate as volume targeted pressure support mode according to the spontaneous respiratory rate. The amount of pressure support gradually decreases once the spontaneous breathing of the patient is adequate to maintain the oxygenation and ventilation parameters. This advantage offered by ASV mode is widely used as a weaning mode of the mechanically ventilated patient.

Various studies have been conducted on ASV mode comparing its efficacy and safety during weaning phase in various groups of the patients including postoperative, cardiac and COPD patients. Most of these studies have demonstrated that the automated weaning using ASV mode offered rapid recovery and faster tracheal extubation without any significant complications. ${ }^{5,6}$
In clinical practice, the mechanically ventilated patients are usually weaned using conventional mode like pressure support, continuous positive airway pressure(CPAP) and T-piece but very few literatures are available on ASV using as weaning mode. In our study, we used ASV as a sole mode of mechanical ventilation, until the trachea was extubated, and observed the outcome in terms of duration of mechanical ventilation, weaning duration and length of ICU stay.

\section{METHODOLOGY}

Our study was prospective observational study carried out in the 14-bedded adult multi-disciplinary intensive care unit (ICU) of a tertiary care hospital (Birat Medical College and Teaching Hospital, Biratnagar) for a duration of six months between September 2015 and February 2016. The ethical clearance was obtained from the institutional review committee (IRC) and informed consent was taken from the next to kin of the patient. Patients aged 18 to 60 years without significant renal, liver, or severe impairment of left ventricular function requiring invasive mechanical ventilation for type 1 or type 2 respiratory failures were included in the study. We included all patients who met the inclusion criteria for the study during the mentioned duration.

The decision regarding invasive mechanical ventilation was made jointly by the primary physician and the intensivist on the basis of clinical parameters and arterial blood gas parameters which included tachypnea, tachycardia, use of accessory respiratory muscles, systolic blood pressure less than $90 \mathrm{mmHg}$ requiring inotropic support, PO2 less than 60 $\mathrm{mmHg}, \mathrm{PCO} 2$ more than $50 \mathrm{mmHg}$ or severe acid-base abnormalities.

The trachea was intubated orally with $8 \mathrm{~mm}$ size endotracheal tube in order to avoid high airway resistance with the use of smaller size tube. The patient was then connected to the ventilator (Hamilton C2, Switzerland) on adaptive support mode. The ideal body weight of patient was calculated on the basis of height and minute ventilation was set initially at $100 \mathrm{ml} /$ ideal body weight. We started with $100 \%$ support of the calculated minute ventilation with a 
PEEP of $5 \mathrm{~cm}$ of $\mathrm{H}_{2} \mathrm{O}$ and $\mathrm{FIO}_{2}$ of $100 \%$. The $\mathrm{FIO}_{2}$ was gradually decreased to a minimum level in next two hours so that the oxygen saturation was maintained at least more than $94 \%$. The percentage of minute ventilation, PEEP and $\mathrm{FIO}_{2}$ were manipulated whenever necessary in order to keep $\mathrm{PO}_{2}$ and $\mathrm{PCO}_{2}$ within acceptable range.

The weaning decision was made when the clinical condition of the patient improved satisfactorily. The weaning was started by gradually decreasing the percentage of minute ventilation support by $10 \%$ every two hours to the minimum level of $60 \%$. The peak and mean airway pressure were observed for two hours once the ventilatory parameters such as minute ventilation (60\%), PEEP(5 $\left.\mathrm{cmH}_{2} \mathrm{O}\right)$ and $\mathrm{FIO}_{2}$ (30\%) were achieved at a minimum level. ABG was repeated at the end of two hours of weaning trial and trachea was extubated if the following parameters were met:

\section{Extubation Criteria: ${ }^{7}$}

$>\mathrm{PO}_{2} / \mathrm{FIO}_{2}$ ratio more than $150-200$ with $\mathrm{FIO}_{2}$ less than $50 \%$ and PEEP less than $8 \mathrm{cmH}_{2} \mathrm{O}$

> $\mathrm{PCO}_{2}$ normal or at the baseline level.

$>$ Patient is able to initiate inspiratory effort.

$>\quad$ HR less than 140 per minute

$>$ Blood pressure adequate with no or minimal inotropic support.

\section{Patient can be aroused}

We defined the duration of mechanical ventilation as the time from the start of invasive mechanical ventilation to the tracheal extubation.
Weaning duration was defined as the time from the start of weaning intervention till the trachea was extubated successfully. We considered weaning process successful when the patient is free from any kind of positive ventilatory support (invasive or noninvasive) for more than 48 hours after tracheal extubation. Similarly, we defined the length of ICU stay as the time from admission to the discharge or death of the patient.

\section{RESULTS}

During the six months period of the study, a total of 680 patients were admitted in our intensive care unit out of which 187 patients required invasive and noninvasive mechanical ventilation. Only 78 patients who were mechanically ventilated met the inclusion criteria and were eventually included in the study. The results were analyzed using SPSS 17, a software designed for quantitative data analysis. Parametric continuous data are expressed as mean (SD); non-parametric continuous data are presented as median (interquartile range), and categorical data as number (\%).

The demographic parameters were non-significant and are illustrated in the table 1 . None of the patients in our study had significant liver and renal disease neurological disease while 19 patients had history of hypertension and were on antihypertensive agents. Eleven patients had diabetes mellitus out of which 8 patients under good control of blood sugar by oral hypoglycemic agents. Similarly, 4 patients revealed history of previous renal disease in the form of renal, uretic calculi and one patient had undergone dialysis too.

\section{Table 1: Demographic profile}

\begin{tabular}{lll}
\hline Age in years ( mean \pm SD) & & $48.6 \pm 10.11$ \\
\hline Weight in kg ( mean \pm SD) & $57.34 \pm 12.45$ \\
\hline Sex $(n)$ & Male & $53(67.9 \%)$ \\
\hline Baseline aspartate Transaminase (IU/L) & $25(32.1 \%)$ \\
\hline Baseline Creatinine mg/dl & Female & $21(15-34)$ \\
\hline Hypertension $(n)$ & $0.85(0.6-1.8)$ \\
\hline Diabetes Mellitus (n) & $19(24.3 \%)$ \\
\hline Renal Disease $(n)$ & $11(14.1 \%)$ \\
\hline
\end{tabular}


The initiation of mechanical ventilation was made mainly on the basis of initial arterial gas parameters (Table 2). The first arterial blood gas showed $80.7 \%$ of patients had type 1 respiratory failure with mean $\mathrm{PO} 2$ of $45.62 \mathrm{~mm} \mathrm{Hg}$ while $19.2 \%$ patients had type 2 respiratory failure with the mean pCO2 of $68 \mathrm{~mm} \mathrm{Hg}$.

\section{Table 2: Initial blood gas parameters}

\begin{tabular}{|ll|}
\hline Type 1 Respiratory Failure $(\mathrm{n})$ & $63(80.7 \%)$ \\
\hline Mean PO2 for type 1 Failure & $45.62 \pm 8.8$ \\
\hline Type 2 Respiratory Failure $(\mathrm{n})$ & $15(19.2 \%)$ \\
\hline Mean PCO2 for Type 2 & $68.11 \pm 12.15$
\end{tabular}

The various ventilator parameters were recorded at least three times a day till the trachea was extubated and the mean of the various parameters were calculated as shown in Table 3. We observed that the mean fraction of inspired oxygen was $37 \%$, mean of respiratory rate was 18 breaths per minute, and mean tidal volume was $7 \mathrm{ml}$ per $\mathrm{kg}$ ideal body weight. Similarly, the patient had peak airway pressure of 18 $\mathrm{cm} \mathrm{H}_{2} \mathrm{O}$ while mean airway pressure was $9.45 \mathrm{~cm}$ of $\mathrm{H}_{2} \mathrm{O}$. The bronchodilator therapy in the form of salbutamol and ipravent nebulization was used in order to keep airway pressure under control whenever required. The mean of the PEEP was maintained at $5.2 \mathrm{~cm}$ of $\mathrm{H}_{2} \mathrm{O}$.

\section{Table 3: Ventilator parameters}

\begin{tabular}{ll} 
Flo2 $(\%)$ & $37.54 \pm 10.21$ \\
\hline Respiratory Rate (per min) & $18.11 \pm 4.2$ \\
Tidal Volume $(\mathrm{ml} / \mathrm{kg})$ & $7.1 \pm 3.2$ \\
Peak Airway Pressure $\left(\mathrm{cmH}_{2} \mathrm{O}\right)$ & $18.25 \pm 6.32$ \\
Mean Airway Pressure $\left(\mathrm{cmH}_{2} \mathrm{O}\right)$ & $9.45 \pm 3.2$ \\
PEEP $\left(\mathrm{cmH}_{2} \mathrm{O}\right)$ & $5.2 \pm 0.1$
\end{tabular}

We observed the clinical outcome of the patient in terms of duration of mechanical ventilation and length of ICU stay (Table 4). The average duration of mechanical ventilation was observed to be 5.4 days while the patient took anaverage of 13 hours to wean from the ventilator. Fourteen patients in our study failed the initial trail ofweaning process and had to offersecond trail that was successful. The mean length of total ICU stay was 6.3 days and seven patients got re-admitted.

\section{Table 4: Clinical outcome and complication}

\begin{tabular}{ll}
\hline Duration of Mechanical Ventilation (Days) & $5.4(3-9)$ \\
Weaning Duration (Hours) & $13.21 \pm 10.2$ \\
ICU Stay (days) & $6.3(2-10)$ \\
\hline Infective Complication (VAP) (n) & $9(11.5 \%)$ \\
Arrhythmia (n) & $13(16.6 \%)$ \\
Re-Intubation (n) & $2(2.5 \%)$
\end{tabular}

During our study, we observed some complications during the weaning process. Nine patient developed ventilator associated pneumonia and these patients required alonger duration of mechanical ventilation as well as longer weaning hours. Similarly, arrhythmia in the form of sinus tachycardia and ventricular ectopic were observed in 13 patients during the whole length of mechanical ventilation. Two patients required re-intubation after first tracheal extubation.

\section{DISCUSSION}

ASV has been widely used for initiation, maintenance and weaning of mechanically ventilated patients as it offers lung protective ventilation. ASV analyses the changing lung dynamics in every breath and uses this feedback mechanism to optimize the subsequent breath according to the need of the patient that decreases work of breathing significantly.

We included 78 patients from our intensive care unit admitted for mechanical ventilation and we offered ASV mode for all the patients in the study. We excluded patient with significant liver, renal as well as neurological disease as these factors have a tendency to delay the weaning process or contribute longer duration of mechanical ventilation and longer ICU stay.

The observation showed that the minute ventilation and airway pressures (both peak and mean) were adequately maintained through out the length of ventilation optimizing the oxygenation and ventilation. We observed that the respiratory rate and tidal volume, as well as mean airway pressure, were automatically adjusted according to the lung dynamics of the patient that helped to prevent auto-PEEP and accelerated the weaning process.

In most of our cases, the lung oxygenation and ventilation improved significantly within 72 hours of starting ventilation and patients were ready to initiate weaning process from 48 to 72 hours. As in previous studies, we considered weaning process once the mean airway pressure is less than $10 \mathrm{~cm} \mathrm{H}_{2} \mathrm{O}$ along with the clinical assessment for optimal oxygenation 
and ventilation. ${ }^{8}$ The trachea was successfully extubated in a mean duration of 13 hours. ASV offered smooth weaning process without any significant complications. The previous study comparing ASV with conventional mode of ventilation reported shorter duration of duration of intubation and mechanical ventilation in postoperative coronary bypass surgery. ${ }^{9.10}$ In another study comparing ASV mode with SIMV and PSV showed shorter duration of mechanical ventilation and very few manipulation to change the ventilator settings with ASV in post cardiac surgery patients. ${ }^{6}$

We observed that the length of ICU stay was not significantly altered as we consider the ICU stay is affected by many factors. However, faster weaning and shorter duration for extubation can contribute for early discharge from ICU. ${ }^{11}$

Our observation also showed a handful of complications during the weaning process. Ventilator-associated pneumonia is an unavoidable complication associated with invasive ventilation. Despite this, the patient compliant ventilation mode and shorter duration of ventilation can contribute to the fewer VAP incidence. Two patients in our study needed re-intubation for secondary causes.
Our study was an observational study only and the outcome cannot be generalized, especially to the patients with respiratory disease. Randomized comparative trials are needed in a wide spectrum of patients in order to further assess the safety of ASV mode.

\section{CONCLUSION}

Adaptive support ventilation is a dual control mode that adapts ventilator pattern in terms of respiratory rate and tidal volume according to the lung dynamics, offering a better patient compliance and decrease work of breathing. It provides automatic weaning mode once the patient starts breathing actively and adequately. Our experiences with ASV mode suggest that this close loop ventilation can be used as a sole mode of mechanical ventilation that optimizes the lung physiology breath to breath and can be effectively used as an automatic faster weaning mode.

\section{ACKNOWLEDGEMENT: None}

\section{CONFLICT OF INTEREST: None}

\section{REFERENCES:}

1. Iotti GA, Polito A, Belliato M, Pasero D, Beduneau G, Wysocki M, et al. Adaptive support ventilation versus conventional ventilation for total ventilatory support in acute respiratory failure. Intensive Care Med. 2010;36:1371-9.

2. Campbell RS, Sinamban RP, Johannigman JA, Luchette FA, Frame SB, Davis $\mathrm{K}$, Jr, et al. Clinical evaluation of a new closed loop ventilation mode: Adaptive supportive ventilation (ASV) Crit Care. 1999;3:P038.

3. Campbell RS, Branson RD, Johannigman JA. Adaptive support ventilation. Respir Care Clin N Am. 2001;7:425-40.

4. Linton DM, Renov G, Lafair J, Vasiliev L, Friedman G. Adaptive Support Ventilation as the sole mode of ventilatory support in chronically ventilated patients. Crit Care Resusc. 2006;8:11-45.

5. Fang Zhu,Charles D, Gomersall, Siu Keung Ng, Malcolm J, Underwood, Anna Lee. Randomized controlled trial comparing adaptive-support ventilation with pressure-regulated volumecontrolled ventilation with automode in weaning patients after cardiac surgery. Anesthesiology 2008; 109:81-7.
6. Petter AH, Chioléro RL, Cassina T, Chassot PG, Müller XM, Revelly JP: Automatic "respirator/ weaning" with adaptive support ventilation: The effect on duration of endotracheal intubation and patient management. Anesth Analg 2003; 97:1743-50.

7. MacIntyreNR.Evidence-based assessments in the ventilator discontinuation process. Respir Care 2012;57:1611-1618

8. Richard D Branson. Modes to Facilitate Ventilator Weaning. Respiratory care 2012;57:10.

9. Sulzer CF, Chioléro R, Chassot PG, Mueller XM, Revelly JP: Adaptive support ventilation for fast tracheal extuba- tion after cardiac surgery: A randomized controlled study. Anesthesiology 2001; 95:1339-4.

10. Cassina $T$, Chiolero $R$, Mauri $R$, et al. Clinical experience with adaptive support ventilation for fast-track cardiac surgery. $\mathrm{J}$ Cardiothorac VascAnesth 2003; 17: 571-575.

11. Van Mastrigt GA, Heijmans J, Severens JL, Fransen EJ, Roekaerts P, Voss G, Maessen JG: Short-stay intensive care after coronary artery bypass surgery: Randomized clinical trial on safety and costeffectiveness. Crit Care Med 2006; 34:65-75. 